\title{
GASTRIC SECRETION IN FEVER AND INFECTIOUS DISEASES
}

\section{BY HSIAO-CH'IEN CHANG}

\author{
(From the Department of Medicine, Peiping Union Medical College, Peiping)
}

(Received for publication September 12, 1932)

In febrile conditions derangement of gastric function constitutes one of the common symptoms. It may be either in the form of motor disturbance or manifested as secretory anomaly. For instance, nausea or vomiting frequently marks the onset of many acute infections. Anorexia as a rule persists throughout the course of such illness. These phenomena point to an impairment of the tone and motility of the stomach and have been attributed to the action of toxins on the gastric musculature (1) (2). They usually disappear after the disease process subsides. The secretory disturbance, on the other hand, may not be quite so apparent. Nevertheless it is not any less common. Achlorhydria has been found in various acute and chronic febrile diseases (3) (4). Faber (5) in discussing the etiology of achylia especially emphasized the importance of these febrile diseases as factors causing complete suppression of the gastric secretion. He believes that typhoid fever, more than any other infectious disease, is frequently complicated or followed by achlorhydria because in this disease there exists an intestinal infection and the stomach is therefore more easily affected. Faber also interprets the secretory changes on the basis of an anatomical lesion, probably in the form of gastritis. It is his opinion that the postfebrile anacidity is very likely to remain for the rest of the patient's life. While infection and intoxication have been generally held as the explanation of the observations quoted above, Meyer, Cohen and Carlson (6) have approached the relationship from another point of view. In their animal experiments these authors were able to obtain the same change in the gastric juice from fever and from application of external heat. Under both of these conditions gastrin, injected subcutaneously, failed to induce a normal secretion. When the temperature became normal the restoration of gastric function was prompt. This definite but transitory depression of the gastric gland cells was therefore considered to be directly produced by the elevation of temperature.

Most previous clinical observations concerning the gastric secretion in fever have been made with the Ewald meal. As the meal stimulus is not reliable as a means of detecting the capability of the stomach to secrete acid these observations require confirmation under conditions of maximum 
stimulation. Moreover views regarding the pathogenesis and duration of postfebrile gastric anacidity have not been uniform and it seems desirable to elucidate these questions further. In the present investigation histamine was employed as the stimulus and a special attempt was made to follow the behavior of the gastric glands after the subsidence of fever.

\section{MATERIAL}

This report is based on a part of the gastric analyses on 1000 patients by the histamine methods done in this clinic. The subjects were all patients in the Peiping Union Medical College Hospital. They suffered from various infectious diseases, mostly typhus fever, typhoid fever, and pneumonia (Table 1). In all 106 cases were studied. Of these only 17 or approximately 16 per cent had had fever for more than two months and might be classified as chronic cases. The average duration of fever for the remaining cases was $14.9 \pm 0.7^{1}$ days. The temperature of the patients at the time of examination ranged between $37.4^{\circ}$ and $41.3^{\circ} \mathrm{C}$., the average being $39.16 \pm 0.07^{\circ} \mathrm{C}$. All but five patients were between 10 and 39 years of age. In no case was the age less than 10 years. One hundred and one patients were male and five were female. The normal values shown in Table 2 and Figures 1, 2 and 3 are from data of Chang and Chang (8).

TABLE 1

Diagnosis Diagnoses of the patients examined Number

Typhus fevier............................. 31

Typhoid fever................................ 21

Paratyphoid fever................................ 4

Pneumonia ............................... 13

Pulmonary tuberculosis.................................... 9

Tuberculosis of peritoneum ..................... 6

Upper respiratory infection. $\ldots \ldots \ldots \ldots \ldots \ldots \ldots \ldots \ldots, 4$

Kala-azar......................................... 4

Lung abscess............................... 3

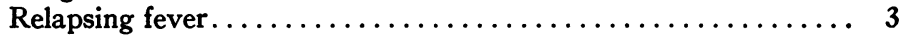

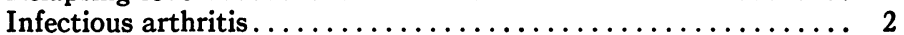

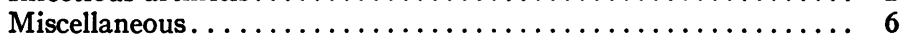

Total .............................

${ }^{1}$ In the text and tables of this article the figure following a \pm sign is the probable error of the mean (calculated according to the usual formula, P.E.m $=0.6745 \frac{\sigma}{\sqrt{N}}$ ), or of the coefficient of correlation (calculated by the formula P.E.r $\left.=0.6745 \frac{1-r^{2}}{\sqrt{N}}\right)$. The values of means and coefficients of correlation are calculated by the ordinary formulae. 


\section{METHOD}

The method was as reported previously (7) (8). Briefly described, the procedure consisted of completely emptying the fasting stomach and removing for examination all the secretion produced within the first 20 minutes after the administration of histamine. The dose of histamine was $0.5 \mathrm{mgm}$. in the form of ergamine acid phosphate (Burroughs Wellcome). As most of these patients had very high fever the withholding of fluids by mouth could not be carried out longer than 4 or 5 hours. Evidently one could not well rule out the dilution factor and the examination of fasting juice was not expected to be of much value. Hence only the findings of the secretion produced within the first 20 minutes after histamine stimulation have been compiled and compared with the normal standard obtained by the same technic (8). In every case no food in any form was allowed for $\mathbf{1 2}$ hours before the examination and the preliminary aspiration of the fasting juice was done as completely as possible. Careful standardization of the technic was aimed at and the results of the different examinations were strictly comparable. On the whole the patients stood the examination remarkably well and experienced no unpleasant effect as a result of it. Specimens of the gastric juice were examined as to volume, acidity, and total chloride. The free and total acidities were titrated with $\mathrm{N} / 10 \mathrm{NaOH}$ solution using dimethylamino-azobenzene and phenolphthalein as respective indicators. The total chloride was determined by Van Slyke's method (9).

\section{RESULTS}

Average acidities and volume of secretion. The mean volume and acidities of the gastric juice produced in the first 20 minutes after histamine stimulation are tabulated in Table 2 and their comparison with the normal standard is graphically illustrated in Figures 1,2 and 3. The figures for free $\mathrm{HCl}$ do not include cases of achlorhydria, while those for the total acidity and the volume of secretion represent the mean of the whole series. It may be noted that all these are very much lower than the normal averages reported elsewhere (8) (see footnote to Table 2). The acidities are about one-third of the normal values after histamine and only approximate the findings of the normal fasting juice. In other words, even on maximum stimulation with histamine the majority of the patients with fever did not secrete much more acid than a normal individual does in the absence of any stimulus. The decrease in the volume of secretion amounts to about 50 per cent. The total chloride shows a less marked reduction than either the acid or the volume, for the mean total chloride content of the febrile patients was $0.332 \pm 0.007$ per cent as compared with the normal value of $0.448 \pm 0.003$ per cent. The significance of this difference will be discussed later. 
TABLE 2

Mean volume, acidities and total chloride content of the gastric juice produced within the first 20 minutes after histamine stimulation *

\begin{tabular}{|c|c|c|c|c|c|c|c|}
\hline \multicolumn{2}{|c|}{ Volume } & \multicolumn{2}{|c|}{ Free $\mathrm{HCl}$} & \multicolumn{2}{|c|}{ Total acid } & \multicolumn{2}{|c|}{ Total chloride } \\
\hline Mean $†$ & $\begin{array}{l}\text { Standard } \\
\text { deviation }\end{array}$ & Mean & $\begin{array}{l}\text { Standard } \\
\text { deviation }\end{array}$ & Mean & $\begin{array}{l}\text { Standard } \\
\text { deviation }\end{array}$ & Mean & $\begin{array}{l}\text { Standard } \\
\text { deviation }\end{array}$ \\
\hline$c c$. & $c c$. & $\begin{array}{c}0.1 N \\
\operatorname{per} c e n t\end{array}$ & $\underset{\text { per cent }}{0.1 N}$ & $\stackrel{0.1 N}{\text { per cent }}$ & $\stackrel{0.1 N}{\text { per cent }}$ & per cent & per cent \\
\hline $30.6 \pm 1.2$ & 17.3 & $30.0 \pm 1.6$ & 20.6 & $33.9 \pm 1.5$ & 22.6 & $0.332 \pm 0.007$ & 0.061 \\
\hline
\end{tabular}

* Normal Chinese averages determined by the same technic are as follows: Volume, $54.8 \pm 1.2 \mathrm{cc}$; free $\mathrm{HCl}, 86.0 \pm 1.10 .1 \mathrm{~N}$ per cent; total acid, $92.5 \pm 1.10 .1 \mathrm{~N}$ per cent; and total chloride, $0.448 \pm 0.003$ per cent $(8)$.

$\dagger$ Mean with its probable error.

The question naturally arises as to whether fever alone was responsible for this decrease in the gastric secretory function. Ten of the patients had a blood hemoglobin percentage below 60 . That these anemic patients did not give the lowest degree of acidity was indicated by their

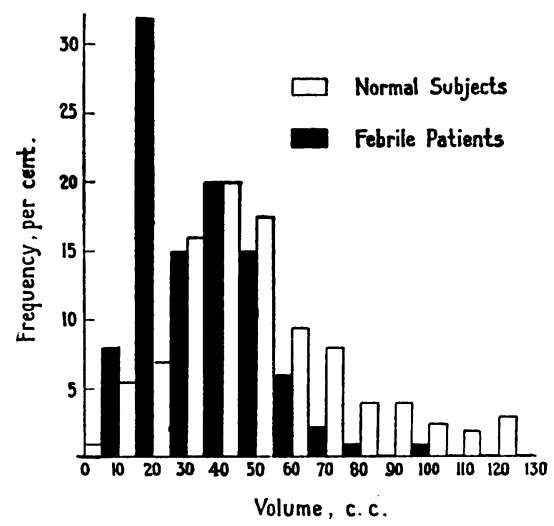

Fig. 1. The Distribution of the Volumes of Gastric Secretion of Febrile Patients Compared with That of Normal Subjects

average acidity (mean total acidity: $38.0 \pm 4.9 \mathrm{~N} / 10$ per cent), which is somewhat higher than that of the total series. Furthermore the mean red blood cell count for the entire group was $4.525 \pm 0.049$ million per cubic millimeter and the mean hemoglobin was $83.9 \pm 1.0$ per cent, both being fairly normal figures. An attempt was made to correlate the degree of acidity with various factors. The correlation coefficient between the total acidity and duration of fever was $+0.031 \pm 0.076$; between the total acidity and hemoglobin was $-0.109 \pm 0.065$; between the total acidity and red blood cell count was $+0.037 \pm 0.063$. All these values are probably insignificant. On the other hand there was a fairly good 
negative correlation between the total acidity and the height of temperature, the coefficient being $-0.500 \pm 0.052$. This inverse relationship between the acidity and the temperature clearly indicates that the latter exerted an important influence over the former. The other factors apparently played no important rôle.

To ascertain further whether the duration of fever had any effect on the gastric acidity the average total acidity of the 17 chronic cases (namely, those having had fever for more than 2 months) was compared with that of the total series. These were $37.8 \pm 4.7$ and $33.9 \pm 1.5 \mathrm{~N} / 10$ per cent respectively, showing no significant difference. At the same time the mean temperature of the chronic cases $\left(38.96 \pm 0.13^{\circ} \mathrm{C}\right.$.) was also quite close to that of the total series. It may therefore be more definitely stated that the reduction of gastric acidity in these cases does not appear to depend on the duration but rather on the height of fever. General physical fitness, which is known to have some influence on the gastric acidity, probably did not have much to do with the findings of the present series, or else the chronically ill patients would not compare so favorably with the acute cases in regard to their gastric secretory function.

Incidence of anacidity. As tested by the indicator dimethyl-aminoazobenzene 33 of the 106 patients showed complete absence of free $\mathrm{HCl}$, giving an incidence of 31.1 per cent. In addition six more patients had free $\mathrm{HCl}$ acidity below 10 N/10 per cent with an equivocal Günzberg reaction. This very high incidence of achlorhydria is in marked contrast with the strikingly low figure (4 per cent) obtained among the normal Chinese (8). In other words almost one-third of the febrile patients secreted no free $\mathrm{HCl}$ while out of every 100 normal subjects only four present this abnormality. As both the normal and febrile series fell in about the same age group this difference is highly significant and should be interpreted as being entirely attributable to some abnormal factor. According to the records none of the patients had suffered before the fever from any condition with which the achlorhydria might have had an etiologic association. Of the ten moderately anemic patients (with a hemoglobin percentage below 60) only two showed anacidity. The average hemoglobin of the achylic group was $80.1 \pm 1.8$ per cent and the average red blood cell count was $4.428 \pm 0.084$ million per cubic millimeter. These figures are not seriously divergent from normal. Anemia, therefore, could not have been related in any important way to the high incidence of anacidity in these patients with fever.

The data for the cases with anacidity were further analyzed with respect to other factors. The mean temperature was $39.58 \pm 0.11^{\circ} \mathrm{C}$. Six of the 33 instances or 18 per cent fell in the group of chronic cases. The average duration of fever of the remaining cases was $16.9 \pm 1.5$ days. All these values were more or less comparable to the corresponding figures of the total group. It may be inferred that the occurrence of achlorhydria 


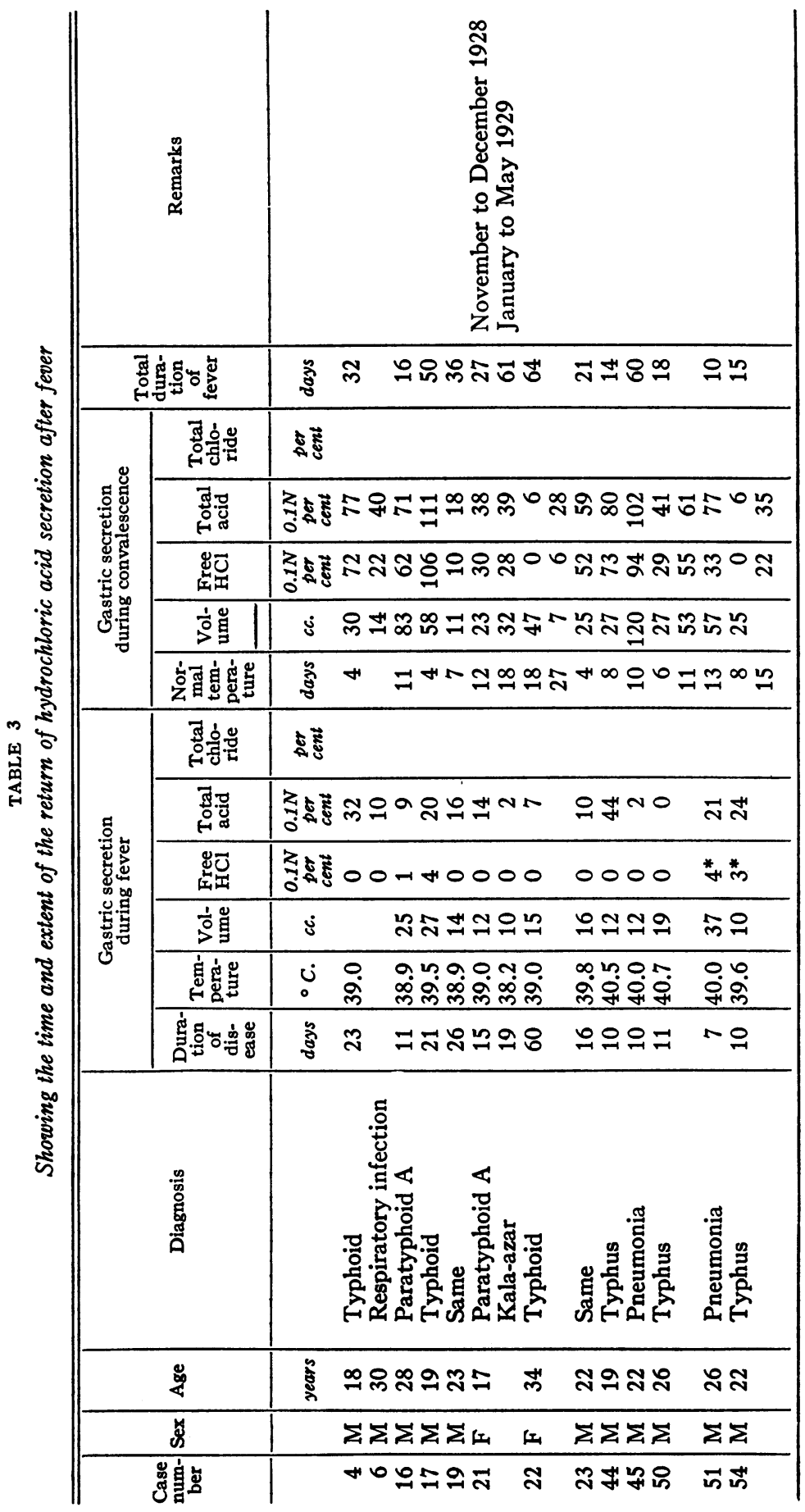




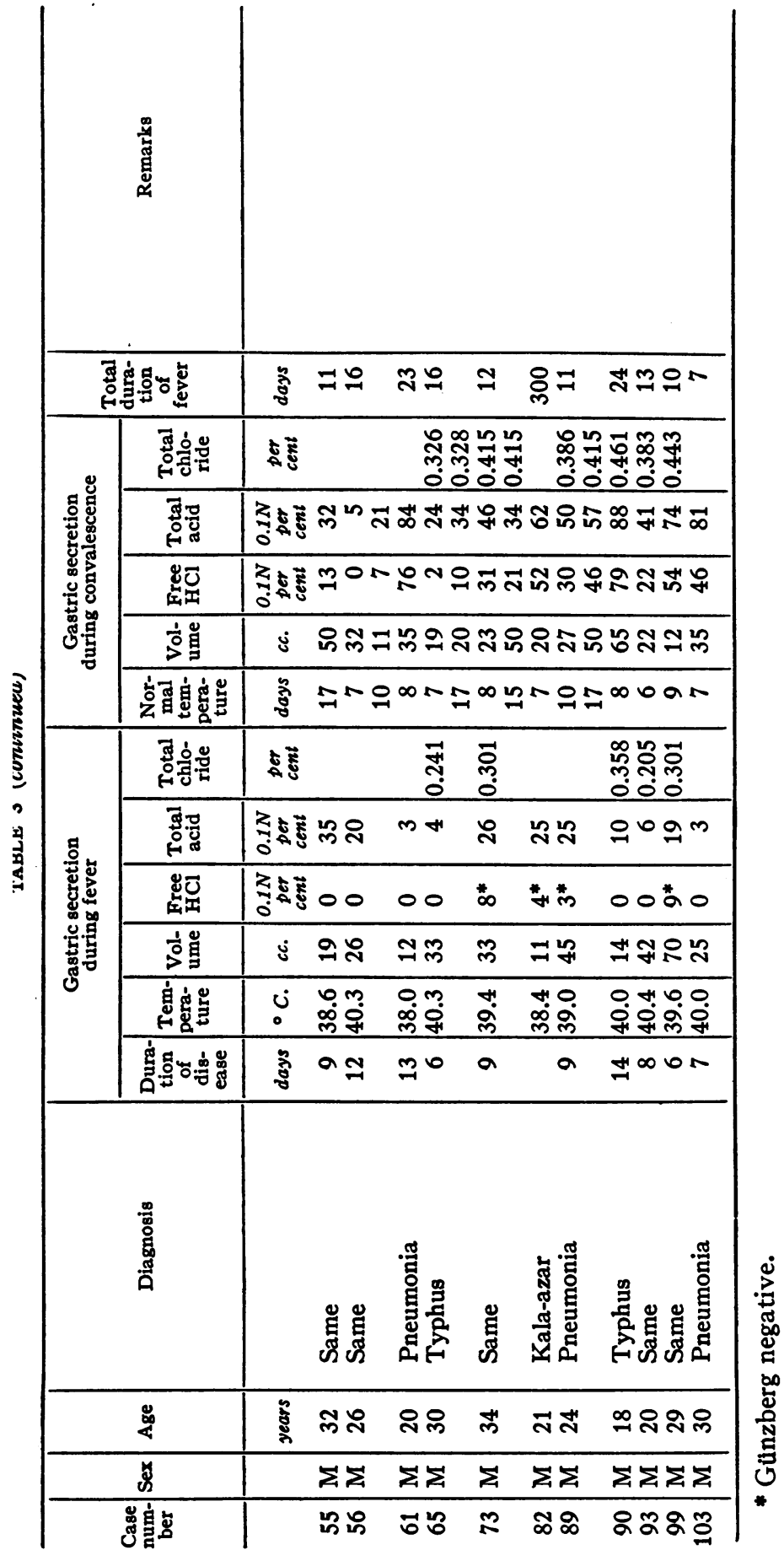


was largely a matter of individual response. That is, with the same degree of fever for approximately the same length of time some patients showed only slight diminution of gastric acidity while others suffered complete inhibition. This is probably to be expected if one takes into consideration the marked variability of gastric acidity in normal subjects.

\section{Gastric secretion after fever}

Fifty-six of the 106 patients, or more than 50 per cent of the cases, were subjected to further examination after the disappearance of fever and recovery from the disease. The interval between the first day of normal temperature and the "follow up" examination varied from 4 to 158 days. According to the behavior of the gastric glands these patients were arbitrarily divided into three groups.

Group 1. Those who were achylic during fever but secreted free $\mathrm{HCl}$ during convalescence (Table 3). They were 24 in number. In them not only free $\mathrm{HCl}$ returned but the total acid and the volume of secretion also increased in amount. When total chloride was tested it too showed a definite rise after the disappearance of fever. The average total acidity of this group was $16.9 \pm 1.6 \mathrm{~N} / 10$ per cent during fever and $59.2 \pm 3.4$ $\mathrm{N} / 10$ per cent on retest. The latter value, though nearly three and a half times the former, was still much lower than the average normal. This might be taken to indicate either that these patients had not completely regained their gastric function at the time the subsequent examination was made or that they originally belonged to the group of "normals" with hypo-acidity. This question is rather difficult to decide, but if one draws an analogy between this group and Group 2, the second hypothesis seems more likely. This will be discussed again.

The case numbered 6 was especially interesting. This patient contracted paratyphoid A fever and kala-azar consecutively in the course of six months. Achlorhydria prevailed during both febrile periods but the acid returned to the same extent soon after each attack of fever.

Group 2. Those who were not achylic and showed increase of acidity after fever (Table 4). These were 26 in number. Their average total acidity during fever was $51.4 \pm 2.0 \mathrm{~N} / 10$ per cent and that after fever $94.7 \pm 1.9 \mathrm{~N} / 10$ per cent, indicating a very definite increase of the gastric function after the temperature became normal. As in Group 1, the total chloride content of the gastric juice after fever was also higher than in the febrile period.

These patients probably belonged to the group of "normals" with hyperacidity, since their mean acidity after fever was actually higher than the average normal. In all probability they were able normally to secrete an abundant amount of acid, so that at the time of fever their gastric acidities were only partially diminished and not inhibited altogether. In contrast, as has been said, the patients in Group 1 might be 
placed in the category of those normally showing hypo-acidity, moderate elevation of temperature in them being sufficient to bring about a complete suspension of the acid secretion. On the cessation of fever the patients in both groups soon recovered the degree of acidity normal for them.

Group 3. Those who showed no increase of gastric acidity after fever (Table 5). Only six patients were in this group. Three of them were achylic. One patient (Case 106) suffering from typhoid fever with relapse showed normal acidity during fever but anacidity in convalescence. She probably fits best in a class of patients described by Faber. Her achylia would be likely to remain. Whether and when the other two patients with achlorhydria would secrete acid again can not be definitely stated. One (Case 101) was followed for as long as five months and free $\mathrm{HCl}$ failed to return within this period. It is interesting to note that this patient also had typhoid fever. The course of his illness was long (108 days) and was complicated by dysentery.

Thus out of 56 patients re-examined 3 or 5 per cent appeared to have developed a seemingly permanent achlorhydria as a result of fever. This figure is not surprising, if one takes into consideration the fact that the incidence of achlorhydria among normal Chinese is about 4 per cent. In other words, these patients might have had the anacidity irrespective of the fever. Except for Case 106, proof of their being able to secrete acid before the occurrence of fever was certainly lacking. The other three patients showed no difference in their gastric acidity during and after the fever. As their acidity was not particularly low, it is perhaps not unreasonable to assume that their gastric function was at most very slightly affected by the febrile state.

\section{DISCUSSION}

The findings described are quite clear cut and speak for themselves. Apparently as a result of fever there occurred a definite impairment of gastric function. This is shown by the fact that the average total acidity decreased by two-thirds as compared with the normal standard and that the incidence of anacidity was eight times the normal. The degree of acidity showed a definite inverse relationship with the height of fever. The duration of fever, the hemoglobin content of the blood, and the general physical fitness apparently played no important rôle. This profound influence of fever on the gastric secretion was, however, only transitory. Nearly 90 per cent of the patients re-examined regained or restored their gastric secretory function soon after the fever and the permanent cases of achlorhydria did not exceed the number that might be expected from a healthy population. Only one convincing case was found (Case 106) in which permanent achylia could be directly attributable to fever. This finding is at variance with Faber's views on the 


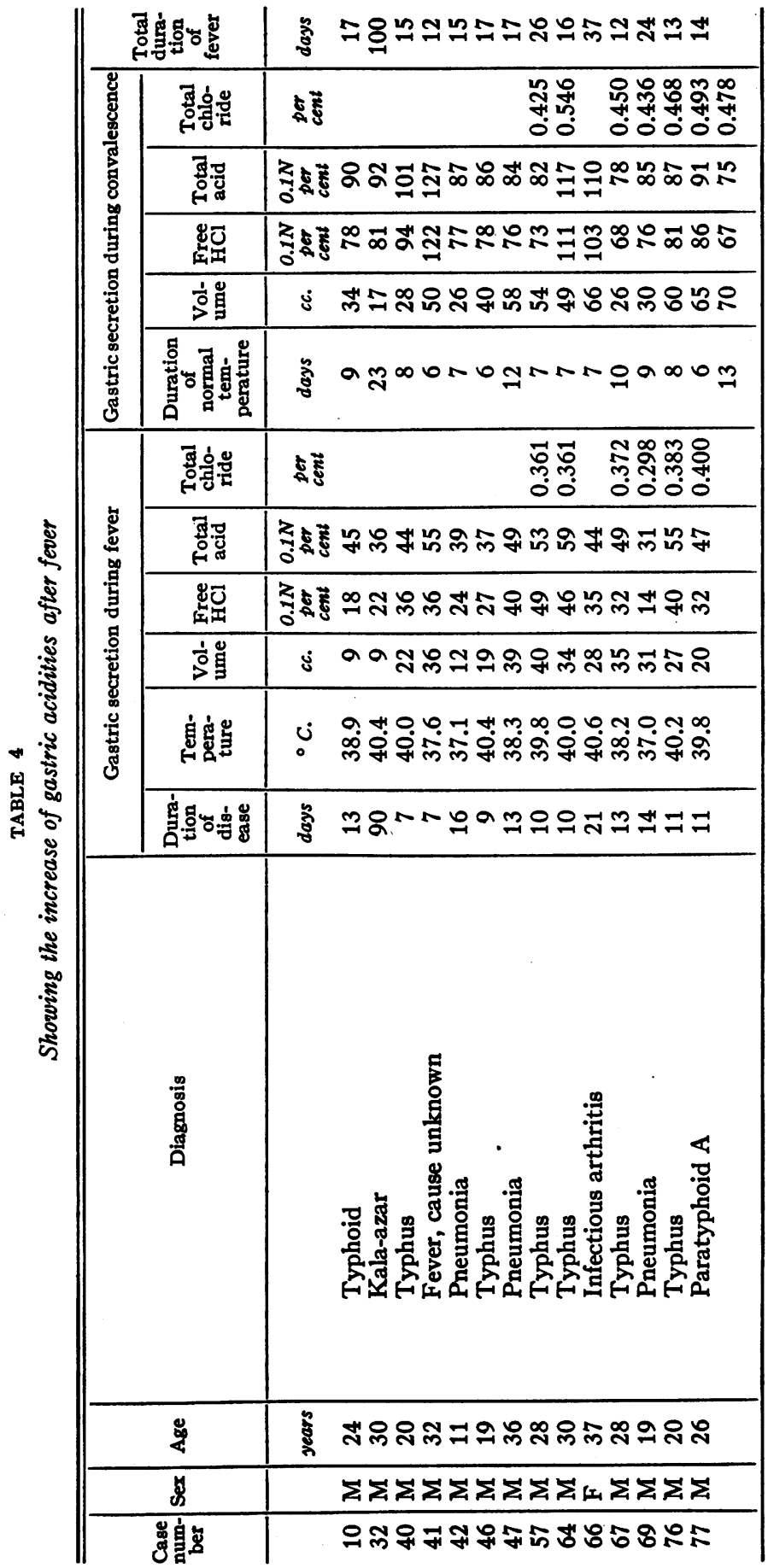




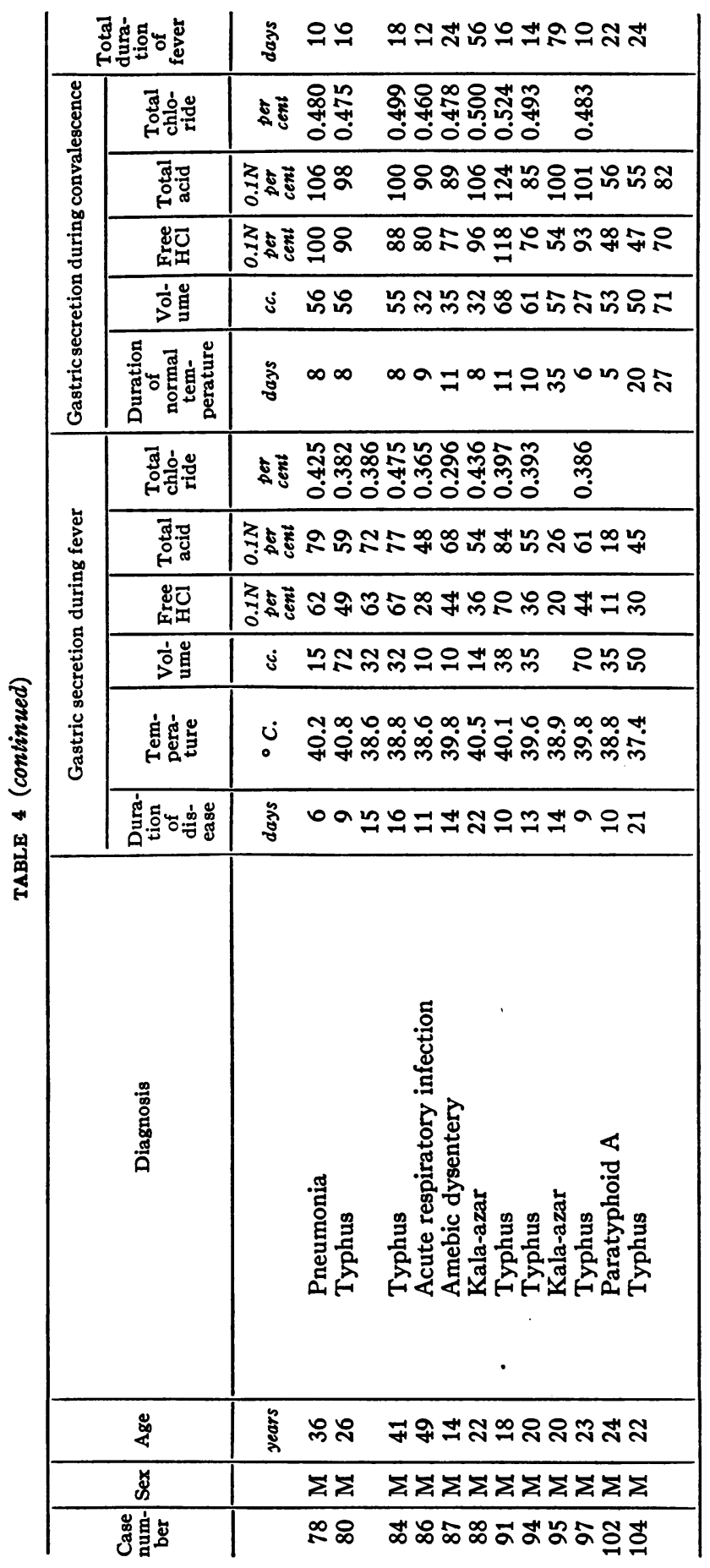




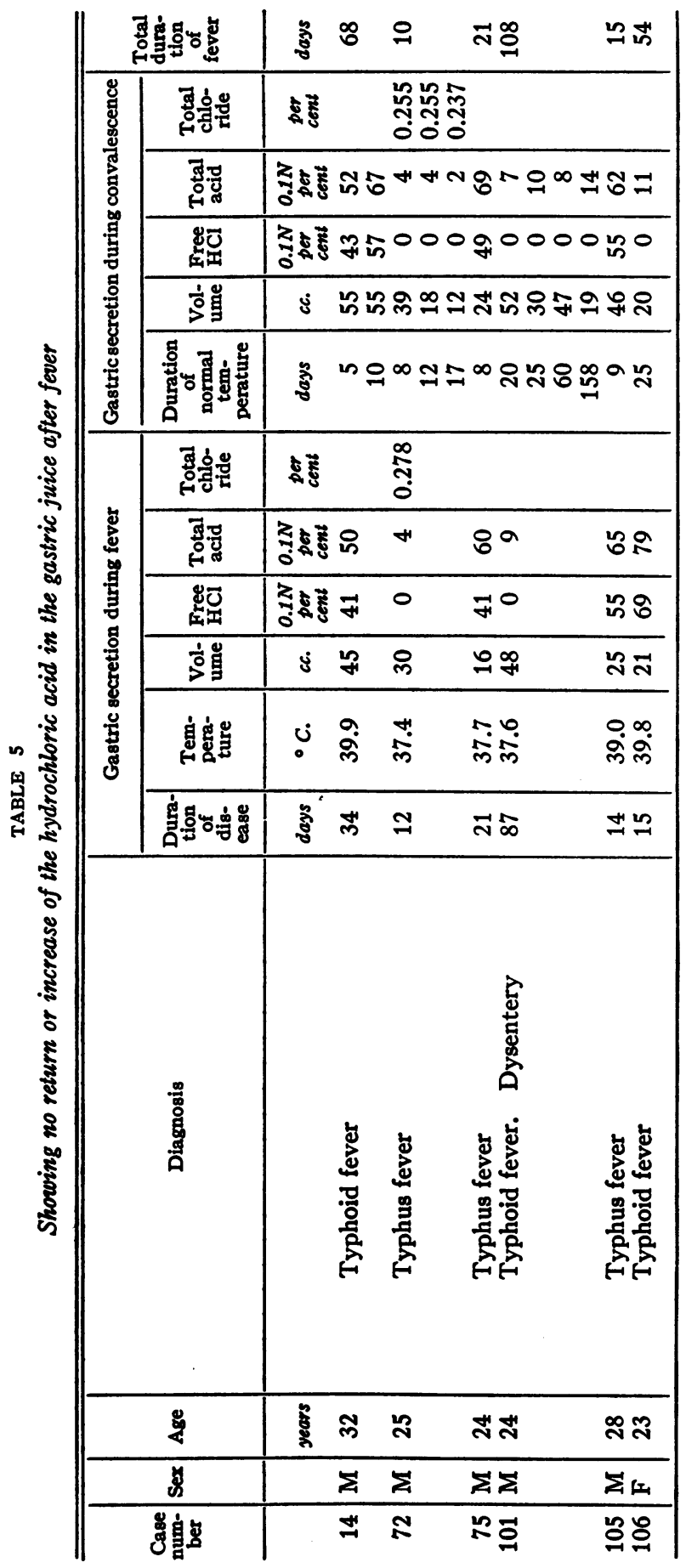


subject. Faber believes that various fevers particularly those associated with an intestinal infection produce gastritis and that the damage done to the secretory apparatus tends to remain. The present

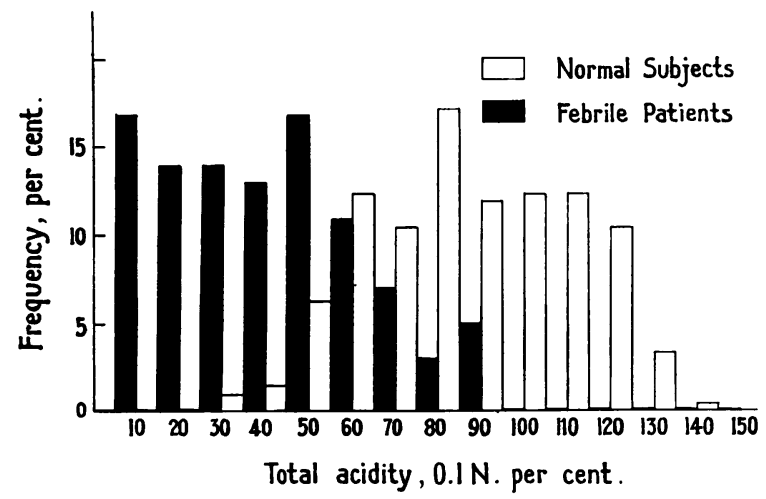

Fig. 2. The Distribution of the Total Acidities of Febrile Patients Compared with That of Normal Subjects

investigation furnished no evidence to disprove the existence of gastritis but if gastritis did exist it certainly did not last long or leave any irreparable damage. One may, therefore, safely conclude that acute infectious diseases are not prominent causes of achlorhydria.

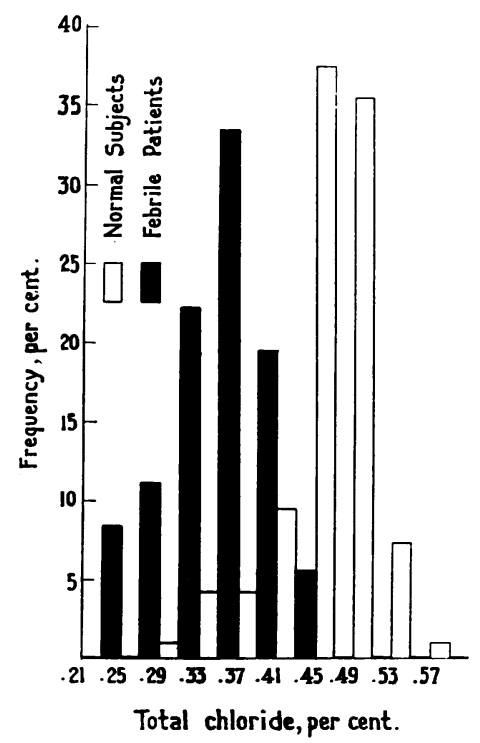

Fig. 3. The Distribution of Total Chlorides of Febrile Patients Compared with That of Normal Subjects

The mechanism by which this lowering of gastric acidity in fever is brought about has yet to be determined. Gastritis is one possibility. 
Nervous or psychic inhibition is another. When the data in Tables 3,4 , and 5 are subjected to careful scrutiny one notices that after fever the increase of free $\mathrm{HCl}$ far exceeds the increases in total acidity and total chloride. As already mentioned the mean total chloride of the febrile patients showed much less deviation from normal than either the mean acidity or the mean volume of secretion. These points seem to argue in favor of duodenal regurgitation as having played a part in reducing the gastric acidity. That the regurgitation of alkaline fluid could not be the sole explanation was well shown by the very definite though less marked increase of the total chloride along with the rise of acidity in convalescence. Mere dilution could not be held to account for the reduction of gastric acidity in fever because the average volume of secretion of these patients was simultaneously reduced to about half the normal amount.

A working hypothesis would be that the mucous membrane of the stomach like many other tissues undergoes certain changes in febrile diseases. These changes are reflected by a temporary loss of function, partial or complete. What takes place in the stomach might well be comparable to cloudy swelling in the kidneys, as has also been suggested by Meyer, Cohen and Carlson (6). Albuminuria while common in many acute infectious diseases usually clears up and permanent renal damage rarely results, except after certain specific infections. May not this analogy apply to the secretory apparatus of the gastric mucosa?

\section{SUMMARY}

1. The gastric function was studied by the histamine method in $\mathbf{1 0 6}$ febrile patients. On the average there was a decrease of the gastric acidity to one-third of the normal. The total chloride and the volume of secretion showed a similar but less marked change.

2. The decrease of gastric function was proportional to the height of fever. Anemia and general physical fitness played no important rôle.

3. Thirty-three of the 106 patients showed achlorhydria, an incidence of 31 per cent. This is about eight times the normal incidence.

4. Fifty-six patients were re-examined in convalescence. Ninety per cent of them recovered their normal gastric function soon after the disappearance of fever. The incidence of "permanent" postfebrile achlorhydria was only 5 per cent, which is not much higher than is expected in a healthy Chinese population. Infectious diseases are probably not important causes of gastric anacidity.

5. This definite but transitory impairment of the gastric function can not be explained on the basis of dilution nor can it be entirely attributable to duodenal regurgitation.

6. An hypothesis is suggested in which the pathologic change in the stomach during fever is compared with cloudy swelling in the kidneys. In both instances the functional disturbance tends to be transient. 


\section{BIBLIOGRAPHY}

1. Ryle, J. A., Gastric Function in Health and Disease. Oxford University Press, London, 1926.

2. Bennett, T. I., The Stomach and Upper Alimentary Canal in Health and Disease. Heinemann, London, 1925.

3. Frankl, T., and Plaschkes, S., Arch. f. Verdauungskr., 1918, xxiv, 309. Klinisch-experimentelle Untersuchungen über die Aetiologie der Kriegsgastritis.

4. Torning, K., Klin. Wchnschr., 1929, viii, 1261. Über die Magensekretion der Phthisiker.

5. Faber, K., Lectures on Internal Medicine. P. B. Hoeber, New York, 1927.

6. Meyer, J., Cohen, S. J., and Carlson, A. J., Arch. Int. Med., 1918, xxi, 354. Contribution to the Physiology of the Stomach. XLVI. Gastric Secretion during Fever.

7. Chang, H. C., Nat. Med. J. China, 1930, xvi, 59. Gastric Analysis by the Histamine Method.

8. Chang, H. C., and Chang, H. L., Chinese J. Physiol., 1932, vi. (In press.) Gastric Secretion of Normal Chinese After Histamine Stimulation.

9. Van Slyke, D. D., J. Biol. Chem., 1923-24, 1viii, 523. The Determination of Chlorides in Blood and Tissues. 